of the long-anticipated changes to cancer care work their way from bench to bedside - ones that would allow precision oncology to be scaled up. In the past year, the US Food and Drug Administration has issued its first approval of a genetic test that can detect mutations in hundreds of cancer-associated genes. Also a first, the agency approved a drug for the treatment of any solid tumour bearing a particular genetic signature, regardless of what tissue the tumour originated in.

Health services around the world are talking up the role of DNA and genomics in a new era of personalized medicine. But the utility of increasingly expensive cancer tests and medications that will help only a minority of patients is also being fiercely debated. Some 30 or so cancer drugs have so far been linked to a specific genetic signature. Many people have benefited, but some will relapse later as their tumours become resistant to the therapy.

Against this backdrop, clinicians are left facing ill people and trying to work out what to do. Whose tumours should be sequenced, and when? How often should one patient's tumour be sequenced? What kind of sequencing should be done -50 genes, 400 genes, a full genome? How should physicians interpret genetic variants and conflicting data?

And over it all hangs the painful question that health-care systems everywhere must grapple with: at what point does the potential for benefit outweigh the cost of sequencing and the treatment that follows?

Researchers can help to pave precision oncology's path to the clinic. More research on cancer genetics might reveal roles for

as-yet-unexplained genetic variants. Such studies would also help researchers to unpick the effects of combinations of genetic variants, a consideration that is likely to become more important as clinicians sequence larger sets of a tumour's genes. Also useful is the growing emphasis in cancer research on testing targeted therapies in combination with one another, and together with drugs that provoke immune responses to cancer. From a clinical perspective, better and

"Clinicians are left facing ill patients and trying to work out what to do." more-thorough screening should identify the people most likely to benefit.

Precision oncology increases the range of treatment options - but so far for only a relatively small number of people. Yet clinicians say that media reports of miracle cures have painted a much rosier picture, fuelled by anecdotes about exceptional responders who experience dramatic, but highly unusual, responses to treatment. In the United States, the problem is compounded by advertisements - from pharmaceutical companies and treatment centres - aimed directly at people with cancer. Enthusiasm for the possibilities of precision oncology has led too many involved to present the option with too much optimism. By its very nature, each precision cancer drug is destined to help only a fraction of people. Everyone with cancer wants, understandably, to be in that fraction. Hope is important. But all parties need to be sensitive to how the promise of precision medicine is communicated to patients - and to their physicians.

\section{Food chain}

\section{European advisers set out a path to a sustainable future for food production.}

$\mathrm{W}$ hen Europe scrapped its chief scientific adviser role and instead installed a committee of experts in 2016, there were questions about how well the system would function. Very well indeed, is the answer - at least if a report released by the expert group on 4 June is anything to go by.

Ostensibly, the opinion document from the European Union's Group of Chief Scientific Advisors discusses how the EU authorizes plant protection products (chiefly insecticides and herbicides). But it goes further, offering sound advice on how to reform aspects of the EU's infamous bureaucracy and convoluted decision-making mechanisms for agriculture. And written between the lines is a clear and simple message, which Europe needs to take on board sooner rather than later: that the region's approach to food production is fragmented and hopelessly unsuited to future needs.

The report is the latest in a series of papers by the group, all "from a scientific point of view". It will feed into specific discussions about, for example, how the commission can better integrate the functions of its agriculture, food, environment and research directorates. That is important if Europe is to set out a coherent plan for a sustainable future. At present, it is too easy for policymaking on a continent-wide level to be paralysed, as seen with research into and applications for genetically modified (GM) organisms. And, as shown by a controversy late last year over the approval of the herbicide glyphosate by the EU, there is insufficient public trust in the process.

The committee was tasked by the European Commission (EC) to work out whether the current system for approval of these products could be more effective, efficient and transparent. The report makes some sensible suggestions for improving transparency, some of which can and should be implemented quickly in the existing approval process. It recommends a new public IT platform to store the relevant data, case studies and information on cultural and historical differences in agricultural practice that need to be built into models that assess risk. It calls for more systematic updates to the assessment of active substances when new data become available. It supports more monitoring and analysis of how pesticides and herbicides accumulate in the environment and in wildlife. And it suggests that mandatory pre-registration of the lab studies that companies will rely on to show their chemical is safe (including the lab location, the types of test planned and what will be learnt from them) would help to address concerns about the independence and objectivity of industry-sponsored studies.

More fundamentally, the report suggests some structural and systemic changes to the approval process. These range from clarifying levels of acceptable risk (current regulations invoke the precautionary principle to demand no harm to health or the environment, which is unachievable in practice), to recognizing that taking no action (for example, not applying a pesticide) also carries risks. Furthermore, the report recommends bringing the risk-assessment process within the control of the EC (it is currently outsourced to member states).

These types of change are more difficult to implement - not least because, at present, nations have control over the process (and, in the GM case, a de facto veto). National politicians will not surrender that control lightly, particularly in countries such as Germany, where antiGM feeling has huge influence.

The particular wisdom of the latest report is in its recognition that, for such political changes to become possible, the focus of the public debate must shift from single issues in agriculture to the bigger question for society - how do we want to create sustainable agriculture in Europe and ensure quality food production, and how much are we prepared to pay for it? Pesticides and herbicides have a part to play, but so do complex and sometimes conflicting issues that have a relationship to agriculture: fertilizers, food chains and environmental protection in general. Tighter controls of pesticides, for example, will affect these other aspects and have costs and benefits to society. Such a discussion will go beyond a strictly scientific point of view, and must account for values and human judgements.

A good start would be for the commission to arrange a high-profile workshop for all relevant parties - including the public, non-governmental organizations, scientists and companies - to kick-start the process. Good advice alone is not enough. 